F. Child Lang. 38 (201 I), 793-808. (c) Cambridge University Press 2010 doi:I0.1017/So305000910000346

\title{
Lexical tone awareness among Chinese children with developmental dyslexia*
}

\author{
WING-SZE LI AND CONNIE SUK-HAN HO \\ University of Hong Kong
}

(Received 30 Fanuary 2009 -Revised Iо November 2009 - Accepted 5 Fune $2010-$ First published online 22 November 2010)

\section{ABSTRACT}

This study examined the extent and nature of lexical tone deficit in Chinese developmental dyslexia. Twenty Cantonese-speaking Chinese dyslexic children (mean age 8; I I) were compared to twenty average readers of the same age (CA control group, mean age 8 ; II), and another twenty younger average readers of the same word reading level (RL control group, mean age $7 ; 4$ ) on different measures of lexical tone awareness, rhyme awareness and visual-verbal paired-associate learning. Results showed that the Chinese dyslexic children performed significantly worse than the CA but not the RL control groups in nearly all the lexical tone and rhyme awareness measures. Analyses of individual performance demonstrated that over one-third of the dyslexic children showed a deficit in some aspects of tone awareness. Tone discrimination and tone production were found to correlate significantly with Chinese word reading. These findings confirm that Chinese dyslexic children show weaknesses in tone awareness.

Learning to read is considered a secondary linguistic activity in that print is linked to the phonology and meaning of a spoken language. Phonological processing skills, especially that of phonological awareness, have been found to be the core contributing factor for the success and the failure of reading in alphabetic languages (e.g. Bradley \& Bryant, I978; McDougall, Hulme, Ellis \& Monk, I 994; Olson, Rack \& Forsberg, I990). Some recent investigations have examined whether these cognitive-linguistic causes are language-specific or language-universal. The Chinese language is an ideal case to examine this universality issue. In terms of script, Chinese characters are visually complex and they map closer onto meaning than to sound. In terms of phonological structure, Chinese language is special for its monosyllabic nature and its presence of lexical tones, unlike alphabetic

[*] Address for correspondence: Connie Suk-Han Ho, Department of Psychology, The University of Hong Kong, Pokfulam Road, Hong Kong. tel: (852) 224I 5652; fax: (852) 285835 I8; e-mail: shhoc@hkucc.hku.hk 
languages, which are most often multisyllabic and non-tonal. Each Chinese character represents a morpheme and is pronounced as a syllable with a fixed grouping of onset, rhyme and tone. A tone is understood as a relative fundamental frequency with a particular pattern which is considered suprasegmental, as it cannot be an independent or discrete part of a word but can only be realized on a syllable or a rhyme (Dinneen, i967).

As in alphabetic languages, phonological awareness has been found to be important in learning to read Chinese. Children's awareness of syllables (e.g. Chow, McBride-Chang \& Burgess, 2005; Ho \& Bryant, I997b; McBride-Chang \& Ho, 2000), as well as of onsets and rhymes (e.g. Siok \& Fletcher, 200I), have been found to be significant predictors to their performance in Chinese word reading. This leads one to wonder if phonological deficit is a cause for developmental dyslexia in Chinese similar to that found in alphabetic languages.

\section{Phonological deficit in developmental dyslexia}

According to Ho, Law \& Ng (2000), Chinese dyslexic children do display deficiency in phonological skills and in onset and rhyme awareness. However, the phonological deficit may account for a relatively small proportion of Chinese dyslexic children's difficulties in reading. In the studies by Ho and her colleagues, only $20-25 \%$ of their Chinese dyslexic children exhibited a deficit in phonological awareness; while around $40-50 \%$ of them manifested slow naming speed or orthographic difficulties (Ho, Chan, Tsang \& Lee, 2002; Ho, Chan, Lee, Tsang \& Luan, 2004). Unlike alphabetic languages, the phonological deficit appears not to be the core cause of developmental dyslexia in Chinese. However, previous studies have not examined tone awareness of Chinese dyslexic children. Since lexical tone is a unique feature of the Chinese language, would Chinese dyslexic children find the mastering of tone discrimination more difficult than that of onset and rhyme? How does tone awareness relate to the mechanics of learning to read Chinese?

Dyslexic children with a phonological deficit may be insensitive to the organization of both segmental and suprasegmental elements of a word; or they may be inaccurate in representing phonological components in the mental lexicon (Swan \& Goswami, I 997; Liberman, Mann, Shankweiler \& Werfelman, I982). It may be difficult or slow for dyslexic children with a phonological deficit to acquire the orthography-phonology correspondence (OPC) rules in Chinese (Ho \& Bryant, I 997a). The OPC rules suggest that the pronunciation of a Chinese character may be derived directly from its phonetic component or indirectly through analogy with characters that share the same phonetic component. For example, the character 胞 [bau I] 'placenta', may be pronounced by referring to its phonetic component, 
包 [bau I] 'wrap' or by analogy with another character that shared the same phonetic component, 鮑 [bau I] 'abalone'. This example demonstrates that the onset, rhyme and lexical tone of the characters are all identical to those of their phonetic component. However, these rules and other related analytical skills on phonology are not normally taught to children through formal education despite their usefulness in predicting the pronunciation of Chinese characters. Instead, children have to be phonologically sensitive enough to discover the relationship between the phonology and orthography of Chinese characters (Ho \& Bryant, I997a). Such development may rely very much on children's phonological sensitivity and experience, which in turn would affect their reading and learning.

In cases when phonetic components provide only partially reliable phonological information, Chinese children typically are able to use subcharacter information to read unfamiliar words (He, Wang \& Anderson, 2005; Ho \& Ma, I 999). However, dyslexic children with poor phonological awareness would face greater challenges, when asked to read low-frequency or irregular words, than average readers at the same reading level (Ho, Chan, Tsang, Lee \& Chung, 2006). Handling lexical tones may be an added challenge for Chinese dyslexic children. In addition to the distinctive drop of predictive accuracy, from $40 \%$ to $23-26 \%$ if tone is taken into consideration (Zhou, I980), of the OPC rules for predicting correct pronunciation of Chinese characters by their phonetic components, the representations of lexical tones, among other phonological elements of a Chinese syllable, are less stable and more likely to undergo decay (Luo \& Weekes, 2004). Dyslexic children may not be able to develop an effective mechanism for capturing the phonological elements, especially those of tones, which are needed for further processing or interpretation.

\section{Lexical tone awareness in Chinese}

Based on the above review, it is reasonable to suggest that awareness of lexical tones is important in learning to read Chinese. Before we look into this topic further, we present a brief account of the lexical tones in Chinese.

Among different Chinese dialects, Cantonese is the dialect that has the largest number of tones and is mainly used by people in Guangdong, southeastern Guangxi, Hong Kong, Macau and distributed Chinese emigrants in different parts of the world (Yue, I972). According to the traditional categorization, there are six long tones and three short tones in Cantonese. Cantonese lexical tones are embedded in syllables in order to be pronounced. A syllable cannot be comprehended unless a certain tone is added onto it. Their integral pattern suggests an unclear but seemingly close relationship between the two phonological elements, which this study aims to reveal. 
So what is lexical tone awareness? Studies examining this topic usually compare the performance of participants in tonal processing versus vowel processing. In the study of Cutler \& Chen (I997), nonwords were constructed by varying one to three phonological elements of a Chinese monosyllabic word. The participants were required to judge whether the auditorily presented stimuli were real Cantonese words or not. The results showed that tone differences were significantly more likely to be overlooked when compared with vowel differences. This finding was consistent with that of Tsang \& Hoosain (1979) when participants were asked to interpret target Cantonese words that differed in tones in the context of a sentence. Several studies on processing Mandarin tones also showed consistently that tonal processing is less efficient when compared with that of vowels (Ye \& Connine, r 999; Taft \& Chen, I 992).

Why is this the case? Taft \& Chen (I992) have suggested that words bearing the same rhyme with different tones may sound perceptually more similar to the listeners than words with different rhymes. This implies that listeners may find it more difficult to differentiate and identify words with different tones than those with different rhymes. In other words, vowels can be perceived more easily. Another possible account would be the difficulty in representing tonal information alone in our working memory, resulting in the hindrance of processing tones in words.

Schirmer, Tang, Penney, Gunter \& Chen (2005) conducted an eventrelated potential (ERP) study to examine the significance of segmental and tonal processing of Cantonese words. The participants listened to semantically incorrect words that differed from the most expected sentence completion at the tone or segmental level. Upon comparing the ERP effects elicited by these two conditions, they reported that the ERP effects were comparable in terms of their amplitude and time course. This suggests that tones, like segmental information, contribute in some ways to lexical processing. Another priming study, conducted by Zhou, Qu, Shu, Gaskell \& Marslen-Wilson (2004), also demonstrated the practical role of lexical tone in speech recognition. They found that tones are sufficient to affect semantic activation in recognizing speech input. This suggests that tonal information is useful in the lexical processing of speech input.

Understanding the role of lexical tone awareness in Chinese is very important as it can contribute to reading success for all children who are learning Chinese. Though a few studies have suggested that phonological skills lacked predictive relationship with Chinese reading (Gottardo, Chiappe, Yan, Siegel \& Gu, 2006), most studies show that phonological skills are significant predictors in reading Chinese words successfully by children (Ho \& Bryant, I 997a; I 997b; Hu \& Catts, I 998; Huang \& Hanley, I994; I997; So \& Siegel, I997). For instance, Chan \& Siegel (200I) reported that poor Cantonese-speaking readers showed more difficulty with 
tone discrimination than normally achieving readers. Similarly, in the study of Siok \& Fletcher (200I) with Mandarin-speaking children, they found that lexical tone awareness showed significant correlations with both onecharacter and two-character word reading. These findings represent some initial evidence supporting the significant role of tone awareness in learning to read Chinese. Further research is required to understand its specific role in reading in comparison with other reading-related skills.

\section{Lexical tone awareness facilitates orthographic and morphological learning}

Tone awareness is important for learning Chinese characters through the orthography-phonology correspondence (OPC) rules. Chinese characters with the same phonetic components are often homophones or partial homophones. Examples are 媽 [ma I] 'mother' and 罵 [ma 6] 'scold', both with the same phonetic component 馬 [ma 5]. The characters are partial homophones of each other. This shows that good tone discrimination is essential for applying the OPC rules effectively for word learning. Eventually this process helps the learning of orthographic regularities in Chinese and facilitates both phonological and phonetic processing.

Chinese, being a morphosyllabic script, relies heavily on decoding each character into its corresponding syllable and morpheme. Accurate tone processing helps to clarify or eliminate confusions between similar words and allows stronger connections to be built between phonological and morphological representations.

\section{Learning arbitrary associations and reading acquisition}

Learning to read involves a continuous process of learning the associations between print and sound. The visual-verbal paired-associate learning (PAL) skill is particularly central to beginning readers of any language as well as readers of languages with arbitrary script-sound associations like Chinese. Windfuhr \& Snowling (200I) tested a group of English-speaking normally achieving primary school children on phonological awareness, PAL and reading skills. Results of hierarchical regression analyses showed that both phonological awareness and PAL independently predicted reading performance. Looking into generalizing such a relationship to Dutch dyslexic children, Messbauer \& de Jong (2003) reported that their Dutch dyslexic children also had difficulty in verbal learning. However, the dyslexic children did not display qualitative differences on phonological errors as compared with the control groups. These findings suggest that both phonological awareness and PAL are significant contributors to the learning of reading in alphabetic languages, and their roles may be independent. Given that the script-sound relationships in Chinese are rather arbitrary, 
it would be meaningful to examine whether phonological awareness (particularly that of tone) and PAL have unique and independent contributions to the learning of reading Chinese, and whether Chinese dyslexic children have deficits in these two areas.

\section{AIMS OF THE PRESENT STUDY}

The aims of the present study were to examine: (I) whether Chinese dyslexic children show difficulties in tone discrimination and production, and in learning paired associations; and (2) the associations of phonological awareness (particularly tone awareness) and PAL with Chinese word reading.

\section{METHOD}

\section{Participants}

Twenty Cantonese-speaking Chinese dyslexic children aged seven to ten (mean age $=8$; I I $S D=\mathrm{I} ; \mathrm{I}$ ), with fifteen boys and five girls, were recruited in the Dyslexia group. They were either referred by the local education authority or recruited from three local primary schools. All the children were previously assessed by the local education authority on an intelligence test and the Hong Kong Test of Specific Learning Difficulties in Reading and Writing (HKT-SpLD) (Ho, Chan, Tsang \& Lee, 2000). The HKTSpLD is a standardized test for the diagnosis of developmental dyslexia with local norms in Hong Kong, consisting of five domains of subtests, namely literacy skills, rapid naming, phonological awareness, phonological memory and orthographic skills. The diagnosis of developmental dyslexia was established when the literacy composite score and at least one of the cognitive composite scores were at least I standard deviation below the mean score of their respective age in the HKT-SpLD. A normal intelligence of IQ 85 or above was also required.

Another forty children were recruited from a representative primary school in Hong Kong as controls. They all spoke Cantonese as their first language and had been living in Hong Kong since birth. Twenty of them matched the Dyslexia group on chronological age (CA control group) (mean age $=8$; I,$S D=0 ;$ Io) and another twenty younger average readers matched the dyslexic children on level of word reading (RL control group) (mean age $=7 ; 4, S D=0 ; 9$ ). They were carefully selected to match the dyslexic children on sex, IQ and reading performance in the Chinese word reading subtest of the HKT-SpLD. On average, children of the Dyslexia group were about one and a half years older than those of the RL control group. This reflected the extent of their reading difficulties (see Table I). 
TABLE I. Characteristics of the three groups of participants

\begin{tabular}{|c|c|c|c|c|c|c|c|c|c|}
\hline \multirow[b]{3}{*}{ Characteristic } & \multirow{2}{*}{\multicolumn{2}{|c|}{$\begin{array}{l}\text { Dyslexia } \\
(n=20)\end{array}$}} & \multirow{2}{*}{\multicolumn{2}{|c|}{$\frac{\text { CA control }}{(n=20)}$}} & \multirow{2}{*}{\multicolumn{2}{|c|}{$\frac{\text { RL control }}{(n=20)}$}} & \multirow[b]{3}{*}{$F(2,57)$} & \multirow{3}{*}{$\begin{array}{l}\text { Partial } \\
\text { Eta Sq. }\end{array}$} & \multirow{3}{*}{$\begin{array}{l}\text { Post hoc } \\
\text { comparison }\end{array}$} \\
\hline & & & & & & & & & \\
\hline & $M$ & $S D$ & $M$ & $S D$ & $M$ & $S D$ & & & \\
\hline $\begin{array}{l}\text { Age (years; } \\
\text { months) }\end{array}$ & 8 ; I I & I ; I & 8 ; I I & $0 ; 10$ & $7 ; 4$ & $0 ; 9$ & $2 \mathrm{I} \cdot \mathrm{I} 7 * * * *$ & 0.426 & $\mathrm{D}=\mathrm{CA}, \mathrm{D}>\mathrm{RL}$ \\
\hline IQ & $102 \cdot 6$ & $9 \cdot 0$ & IO4.5 & $9 \cdot 6$ & $106 \cdot 7$ & $9 \cdot 7$ & 0.95 & 0.032 & $\mathrm{D}=\mathrm{CA}=\mathrm{RL}$ \\
\hline $\begin{array}{l}\text { Chinese } \\
\text { word reading }\end{array}$ & $70 \cdot 1$ & $2 \mathrm{I} \cdot 8$ & $107 \cdot 2$ & $20 \cdot 5$ & $7 \mathrm{I} \cdot \mathrm{I}$ & $26 \cdot 5$ & I $6 \cdot 78 * * *$ & $0.37 \mathrm{I}$ & $\mathrm{D}<\mathrm{CA}, \mathrm{D}=\mathrm{RL}$ \\
\hline
\end{tabular}

**** $p<0.001$.

Note: $\mathrm{D}=$ Dyslexia group; $\mathrm{CA}=\mathrm{CA}$ control group; $\mathrm{RL}=\mathrm{RL}$ control group.

\section{Materials and procedures}

The children were given a non-verbal intelligence test, a Chinese word reading test, five phonological tasks and a PAL task. Other than the intelligence test, all tasks were administered individually to each participant. The standardized instruction and stimuli were presented to the participants over Logitech earphones broadcasted from an IBM or Fujitsu notebook at a comfortable level. The answers of each child were recorded by Audacity, a voice recording program installed in the respective computers. For all the tasks, the verbal stimuli were presented twice. Upon hearing the stimuli, the children had to repeat once to ensure correct perception for further processing and testing.

Raven's Standard Progressive Matrices. This is a standardized test of nonverbal intelligence. There were five sets of twelve items each. Each item consisted of a visual matrix with a missing part. All children were required to choose a visual pattern from six to eight alternatives that best completed the matrix. The raw scores were converted to standardized scores according to the local norm established by the Hong Kong Education Department in 1986.

Chinese word reading. The Chinese word reading subtest of the HKT-SpLD was used. There were a total of I 50 two-character Chinese words arranged in ascending order of difficulty. The children were asked to read the words aloud in the presented order. One point was given for the correct pronunciation of each two-character word.

Tone discrimination. Two tone discrimination tasks, one with lexical items and the other with non-lexical items, were constructed and administered. In each task, there were two sample, two practice and sixteen experimental trials. Syllables of the first four experimental trials in each task shared the same rhyme (e.g. 寢 [tsem 2], 敢 [gem 2], 浸 [dzem 3] for lexical items and [gem 4], [pem 2], [gwem 2] for non-lexical items), but not for the remaining ones. This arrangement allowed the children to begin the tasks with items that required less specific tonal awareness and thus a lower level of difficulty. The 
non-lexical items used in the task were Chinese gap words. The gap words were phonetically legal syllables but did not have meaning. Gap words may be actual words if pronounced in a different lexical tone. An oddity test format was used in both tone discrimination tasks. Children were required to choose the one that differed in tone among the three presented syllables in each trial.

Tone production. Two tone production tasks of the same format were administered to the children with one using lexical items and the other nonlexical items. There were two sample, two practice and twelve experimental trials in each task. The experimental trials comprised two items in each of the six lexical tones and the sequence of presentation was randomized. Like the tone discrimination tasks, gap words were used as non-lexical stimuli. The children were required to produce another syllable (word or non-word) that shared the same tone as the given syllable. The inter-rater agreement on the children's responses was $95 \%$ and $96 \%$ for the lexical and non-lexical items, respectively.

Rhyme discrimination. The format of the rhyme discrimination task was the same as that of the tone discrimination tasks. Only lexical items were included in this task. There were two sample, two practice and sixteen experimental trials. Half of the items shared the same tone among the stimuli in each trial while the rest did not (e.g. [lou I], [to I] and [fo I] for same-tone items, and [gwok 3], [lok 6] and [kei 2] for different-tone items). The children were required to choose the one that differed in rhyme among the three presented syllables in each trial.

Paired-associate learning. This task was a visual-verbal learning task. Five abstract visual figures were developed, like those in Messbauer \& de John's (2003) study. Each figure was a combination of four elements of either straight lines, dots or curves. The figures were clearly distinguishable from one another and did not resemble any real objects or symbols. Five gap words were paired with these visual figures for learning. In the learning part, the five visual-verbal pairs were presented twice and followed by the children repeating the names of the visual figures. This was to ensure that the children heard the names correctly. There were four trials in the testing part. In each testing trial, the children were shown the visual figures one by one in a random order and were asked to produce the name of each figure. Corrective feedback was given in each trial. One point was given for each correct name of the visual figure. The inter-rater agreement of the children's responses was $93 \%$.

\section{RESULTS}

\section{Group comparisons}

Table 2 shows the mean scores and standard deviations of the various tasks for the three groups of participants. Results of analyses of variance and 
TABLE 2. Mean scores and standard deviations of various tasks for the Dyslexia group, its $C A$ control group and the $R L$ control group; and $F$ values for group comparisons

\begin{tabular}{|c|c|c|c|c|c|c|c|c|c|}
\hline \multirow[b]{3}{*}{ Measure (max. score) } & \multirow{2}{*}{\multicolumn{2}{|c|}{$\begin{array}{l}\text { Dyslexia } \\
(n=20)\end{array}$}} & \multirow{2}{*}{\multicolumn{2}{|c|}{$\begin{array}{l}\text { CA control } \\
(n=20)\end{array}$}} & \multirow{2}{*}{\multicolumn{2}{|c|}{$\begin{array}{c}\text { RL control } \\
(\mathrm{n}=20)\end{array}$}} & \multirow[b]{3}{*}{$F(2,57)$} & \multirow{3}{*}{$\begin{array}{l}\text { Partial } \\
\text { Eta Sq. }\end{array}$} & \multirow{3}{*}{$\begin{array}{l}\text { Post hoc } \\
\text { comparison }\end{array}$} \\
\hline & & & & & & & & & \\
\hline & $M$ & $S D$ & $M$ & $S D$ & $M$ & $S D$ & & & \\
\hline $\begin{array}{l}\text { Tone discrimination } \\
\text { (word) (I6) }\end{array}$ & $5 \cdot 60$ & $2 \cdot 14$ & $8 \cdot 45$ & $2 \cdot 87$ & $5 \cdot 75$ & $2 \cdot 02$ & $9 \cdot$ I 2 **** & $0 \cdot 242$ & $\mathrm{D}<\mathrm{CA}, \mathrm{D}=\mathrm{RL}$ \\
\hline $\begin{array}{l}\text { Tone discrimination } \\
\text { (nonword) ( } 6 \text { ) }\end{array}$ & $5 \cdot 25$ & I $\cdot 94$ & $6 \cdot 85$ & $3 \cdot 35$ & $6 \cdot 05$ & I $\cdot 79$ & $2 \cdot$ II & 0.069 & \\
\hline $\begin{array}{l}\text { Tone production } \\
\text { (word) (1 } 2 \text { ) }\end{array}$ & $3 \cdot 35$ & $I \cdot 46$ & $5 \cdot 15$ & $2 \cdot 46$ & $4 \cdot 60$ & $2 \cdot 48$ & $3 \cdot 57^{*}$ & O. I I I & $\mathrm{D}<\mathrm{CA}, \mathrm{D}=\mathrm{RI}$ \\
\hline $\begin{array}{l}\text { Tone production } \\
\text { (nonword) (12) }\end{array}$ & $4 \cdot 15$ & $2 \cdot 56$ & $6 \cdot 50$ & $2 \cdot 37$ & $5 \cdot 40$ & 3.07 & $3 \cdot 84^{*}$ & O. I I 9 & $\mathrm{D}<\mathrm{CA}, \mathrm{D}=\mathrm{RL}$ \\
\hline $\begin{array}{l}\text { Rhyme } \\
\text { discrimination (I } 6 \text { ) }\end{array}$ & $6 \cdot 45$ & $\mathrm{I} \cdot 85$ & $8 \cdot 85$ & $3 \cdot 22$ & $5 \cdot 85$ & $2 \cdot 03$ & $8 \cdot 45^{* * *}$ & 0.229 & $\mathrm{D}<\mathrm{CA}, \mathrm{D}=\mathrm{RL}$ \\
\hline $\begin{array}{l}\text { Paired-associate } \\
\text { learning }(20)\end{array}$ & 4.75 & $3 \cdot 27$ & $4 \cdot 05$ & $3 \cdot 33$ & $4 \cdot 55$ & $8 \cdot 78$ & 0.28 & 0.01 & \\
\hline
\end{tabular}

$* p<0.05 . * * p<0.01 . * * * p<0.00 \mathrm{I}$.

Note: $\mathrm{D}=$ Dyslexia group; $\mathrm{CA}=\mathrm{CA}$ control group; $\mathrm{RL}=\mathrm{RL}$ control group.

post hoc Tukey HSD showed that the Dyslexia group performed significantly worse than the CA control group but similarly to the RL control group in four tasks, namely the tone discrimination task using lexical items, the tone production tasks using both lexical and non-lexical items and the rhyme discrimination task. This suggests that Chinese dyslexic children have some weaknesses in tone and rhyme awareness but not in discriminating the tonal differences of nonwords.

\section{Proportion of dyslexic children with a deficit in tone awareness}

Apart from group differences, we also investigated the proportion of Chinese dyslexic children who exhibited a deficit in tone awareness. As in Ho et al.'s (2002; 2004) studies, individual raw scores of dyslexic children in each of the tone awareness tasks were compared with the mean scores of their age-matched controls. Children who scored I.5 or more standard deviations below the mean of same-age normally achieving readers were regarded as demonstrating a tone deficit. The analysis showed that 35\%, I0\%, I0\% and 50\% of the Chinese dyslexic children in this study exhibited a deficit in tone discrimination (lexical items and non-lexical items) and tone production (lexical items and non-lexical items), respectively. For reference, $20 \%$ of this group of children showed a deficit in rhyme awareness with the same analysis and criterion. This demonstrates that Chinese dyslexic children have a 
deficit in tone awareness, particularly on producing same tones for given nonwords.

\section{The use of rhymed strategy in tone production}

In the tone production task, the children were asked to produce syllables that shared the same lexical tone with the given syllables. Some of the children systematically produced syllables that also shared the same rhyme with the target (e.g. when [bik I] was given as the target stimulus,

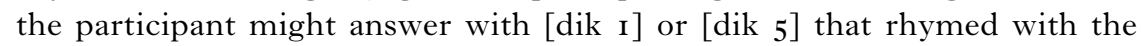
target syllable). We called this a 'rhymed strategy' because the use of such a strategy allowed more phonological similarity between the synthesized and the given syllables. This might, in the end, facilitate the production of syllables that also shared lexical tones and thus boost the performance. The use of a rhymed strategy was calculated by counting the number of syllables produced by the children that had the same rhyme as the target syllables in the tone production tasks regardless of the accuracy of the tones. The average numbers of rhymed strategy used were $7 \cdot 45,9 \cdot 58$ and $8 \cdot{ }^{5} 5$ for the Dyslexia group, CA control group and RL control group, respectively. The use of the rhymed strategy was found to correlate significantly with the performance in Tone production $(r(60)=0.642, p<0.00 \mathrm{I})$. In other words, the children tended to produce more syllables with correct tones if they used the rhymed strategy more. In addition, it was found that the dyslexic children used the rhymed strategy significantly less than their age-matched counterparts $(F(2,57)=3.94, p<0.05)$.

\section{Analysis of phonological errors for the PAL task}

Phonological errors of a PAL task referred to incorrect answers, each with one or more mispronounced phonological elements as compared with the target syllable, given by the participants. These errors were analyzed in order to understand the interference of phonological weakness on learning and memory. For understanding the phonological difficulty of the children, only incorrect answers with one mispronounced phonological element (an onset, a rhyme or a tone) was included for this analysis. Answers which involved two or more mispronounced phonological elements were excluded, as such errors resulted in syllables that were largely different from the target syllables, suggesting inaccurate memory rather than possible phonological confusion. As a whole, the percentages of phonological errors among total errors made by the Dyslexia group, the CA control and the RL control groups were $50 \%, 67 \%$ and $60 \%$ respectively. Table 3 shows the average number of each type of phonological errors. Results of ANOVA $\left(F(2,57)=7.93, p<0.0 \mathrm{I}, \eta_{\mathrm{p}}{ }^{2}=0.2 \mathrm{I} 8\right)$ and post hoc comparison showed that 
TABLE 3. Mean scores and standard deviations of the numbers of three types of phonological errors made by the three groups of children in the PAL task; and $F$ values for group comparisons

\begin{tabular}{|c|c|c|c|c|c|c|c|c|c|}
\hline \multirow[b]{3}{*}{ Type of errors } & \multirow{2}{*}{\multicolumn{2}{|c|}{$\frac{\text { Dyslexia }}{(n=20)}$}} & \multirow{2}{*}{\multicolumn{2}{|c|}{$\frac{\text { CA control }}{(n=20)}$}} & \multirow{2}{*}{\multicolumn{2}{|c|}{$\begin{array}{c}\text { RL control } \\
\qquad(\mathrm{n}=20)\end{array}$}} & \multirow[b]{3}{*}{$F(2,57)$} & \multirow{3}{*}{$\begin{array}{l}\text { Partial } \\
\text { Eta Sq. }\end{array}$} & \multirow{3}{*}{$\begin{array}{c}\text { Post hoc } \\
\text { comparison }\end{array}$} \\
\hline & & & & & & & & & \\
\hline & $M$ & $S D$ & $M$ & $S D$ & $M$ & $S D$ & & & \\
\hline Onset error & $\circ$ & $\circ$ & $\circ$ & $\circ$ & $\circ$ & $\circ$ & NA & $\mathrm{NA}$ & \\
\hline Rhyme error & $\mathrm{I} \cdot 05$ & $\mathrm{I} \cdot 4 \mathrm{O}$ & $I \cdot 50$ & $I \cdot 73$ & 0.80 & 0.89 & $I \cdot 3 \mathrm{I}$ & 0.044 & \\
\hline Tone error & $5 \cdot 50$ & $2 \cdot 37$ & 3.50 & $2 \cdot 04$ & $2 \cdot 95$ & I.96 & $7 \cdot 93^{* * * *}$ & 0.218 & $\mathrm{D}>\mathrm{CA}, \mathrm{D}>\mathrm{RL}$ \\
\hline
\end{tabular}

$* * * p=0.0 \mathrm{I}$.

TA B LE 4. Matrix of partial correlation coefficients among various measures for all the participants after controlling for the effect of differences in age and IQ

\begin{tabular}{lcccr}
\hline Task & 2 & 3 & 4 & 5 \\
\hline I. Chinese word reading & $0.276^{*}$ & $0.269^{*}$ & 0.172 & 0.207 \\
2. Tone discrimination & - & $0.419^{* * *}$ & $0.434^{* * *}$ & -0.005 \\
3. Tone production & & - & $0.430^{* * *}$ & 0.069 \\
4. Rhyme discrimination & & - & 0.1 I 2 \\
5. Paired associate learning & & & & - \\
\hline
\end{tabular}

* $p<0.05$. **** $p=0.001$.

the Dyslexia group made significantly more tonal errors than both the CA and RL control groups in the PAL task.

\section{Associations between tone awareness and other measures}

Table 4 shows the correlation coefficients among the various measures for the three groups combined after controlling for the effect of age and IQ. Composite scores (i.e. average $z$-scores) were computed for the two Tone discrimination tasks and two Tone production tasks, respectively, as each pair was highly correlated with each other (all $r \mathrm{~s}>0.39$, all $p \mathrm{~s}<0.0 \mathrm{I}$ ). It was found that tone discrimination, tone production and rhyme discrimination correlated significantly (all $r \mathrm{~s}>0.4 \mathrm{I}$, all $p \mathrm{~s}=0.00 \mathrm{I}$ ). However, only tone discrimination and production correlated significantly with Chinese word reading (all $r s>0.26$, all $p s<0.05$ ). The results suggest that tone awareness is particularly important for Chinese word reading.

\section{DISCUSSION}

The primary aim of the present study was to examine the extent and nature of lexical tone awareness deficit in Chinese developmental dyslexia. 
In addition, this study also examined the possible relationship between lexical tones as suprasegmental elements and rhymes as segmental elements in Chinese language learning as well as the contribution of lexical tone awareness to the learning of Chinese characters.

\section{Lexical tone awareness in Chinese dyslexic children}

The present findings show that, on average, Chinese dyslexic children manifest weaker tone awareness than same-age children, but comparable to children of the same reading level. This suggests that Chinese dyslexic children may show a developmental delay in processing lexical tones. Our findings are consistent with those of previous research studies that Chinese poor readers performed worse than children of the same age in tone discrimination (Chan \& Siegel, 200 I Chen, Anderson, Li, Hao, Wu \& Shu, 2004).

In this study, at least one-third of the Chinese dyslexic children showed a deficit in some aspects of tone awareness $-35 \%$ of them had difficulty in discriminating the tone of known words and $50 \%$ had difficulty in producing the same tone for a given nonword. Ho and her colleagues reported that only $20-29 \%$ of their Chinese dyslexic children exhibited deficits in onset or rhyme awareness (Ho et al., 2002; 2004). Similarly, the present study also found that $20 \%$ of our dyslexic children showed a deficit in rhyme discrimination. It appears that Chinese (particularly Cantonese-speaking) dyslexic children have a special difficulty in tone processing and such a difficulty may be relatively more severe than their difficulty in processing onsets and rhymes.

In general, it appears that children discriminate the tone of known words better than that of nonwords. This may suggest that dyslexic children have weak representation of the tone information even for words heard many times. In contrast, for tone production, children generally produce the same tones for nonwords better than for known words. When given a nonword, the children were less bound and tended to give both lexical and nonlexical responses, whereas they tended to give mainly lexical responses to word targets. Therefore, there is a greater chance for children to produce a syllable that shares the same rhyme with the nonword target than with the word target. With the use of the rhymed strategy, older normally achieving readers are more efficient at generating the same rhyme-tone responses.

\section{Relationship between awareness of lexical tones and rhymes in Chinese}

The strong correlations between tone discrimination and production and rhyme discrimination suggest that there are links between awareness of lexical tones and rhymes in Chinese. Rhymes are regarded as segmental, 
where each rhyme is a group of separate and distinguishable phonemes. Tones, on the other hand, are attached to rhymes and are known as suprasegmental. These two phonological elements are believed to be lying at two different levels of a word's phonological structure.

Some past studies have suggested that lexical tones are not readily available to help phonological processing as compared with vowels (Taft \& Chen, I 992; Cutler \& Chen, I 997; Ye \& Connine, I 999), because the vowel is situated at a more salient segmental level while tone is suprasegmental and is difficult to represent mentally in isolation. Since tone and rhyme are integral in nature, more skilful readers tend to use the rhymed strategy to help them process tone information. Comparing syllables with same rhymes and different tones help children to pay attention to tonal differences. This suggests that rhyme serves as an indispensable facilitator for children to process lexical tones in Chinese more efficiently. However, Chinese dyslexic children are less efficient in using the rhymed strategy naturally in tone production. They are less capable in isolating tones systematically for processing. In view of the integral relationship between rhymes and tones in Chinese, and the relative difficulty of Chinese dyslexic children in tone processing, the rhymed strategy may be considered as one of the connection points to assist Chinese dyslexic children in achieving lexical tone awareness.

\section{The role of lexical tones on learning pronunciations by Chinese dyslexic children}

In alphabetic scripts, phonological processing skills play a critical role in predicting reading performance. However, such a link in a non-alphabetic orthography such as Chinese has been debatable. Although some studies have reported that phonological processing skills predict reading in Chinese (e.g. Chen et al., 2004; Ho \& Bryant, I 997a; Hu \& Catts, I 998; Huang \& Hanley, I994), the poor reading performance of Chinese dyslexic children may not be fully explained by such a deficit. In contrast, the poor reading performance of Chinese dyslexic children has been attributed to other cognitive deficits, including deficits in rapid naming, as well as in visual and orthographic processing (Ho et al., 2002). Given the relatively simple syllabic structure of Chinese, dyslexic children may have little difficulty in onset and rhyme awareness as shown in past studies. However, the present findings show that Chinese dyslexic children are deficient in tone awareness. In addition, tone awareness, at both the receptive and productive levels, is associated with word reading performance in Chinese. It is understandable that tone awareness is particularly important for learning to read a tonal language. Since tone is suprasegmental and relatively abstract, it appears to be particularly difficult for dyslexic children. We offer below an explanation of how a tone deficit may affect the learning and memory of words for dyslexic children. 
Although the Dyslexia group performed less well than the CA control group in the PAL task, no significant group difference was found. The choice of nonwords as verbal stimuli in the PAL task may have made the task somewhat difficult for all the children (the children on average recalled correctly around only four items out of twenty). Error analyses, however, show that the dyslexic children made significantly more tone errors, but not more onset or rhyme errors, than both CA and RL controls in the PAL task. However, the number of phonological errors made by the dyslexic children was not significantly different from their controls in Messbauer \& De Jong's (2003) study. This discrepancy suggests that dyslexic children have less difficulty in remembering the onsets and rhymes of new words but more difficulty in remembering lexical tones, and this last is important for learning words in tonal languages such as Chinese. The present finding shows that Chinese dyslexic children may have difficulty in learning and remembering the tone of unfamiliar Chinese syllables and reconfirms the tone difficulty of Chinese dyslexic children.

In Chinese, lexical tones are important in giving meanings to characters, as there is a significant number of partial homophones. Even Chinese characters that share the same onsets and rhymes can sound and be defined very differently if the lexical tones differ. For instance, 馬 [ma 5] bears the same onset and rhyme as 媽 [ma I], but differs in tone. The former character means 'horse' while the latter refers to 'mother'. This example illustrates how tonal errors may create chaos in reading and learning. The tone difficulty of Chinese dyslexic children suggests that they would be more inaccurate in learning new associations, at least in the first few instances when the script-sound association has not yet been consolidated, as compared with normally achieving children. In the first few learning trials, dyslexic children may be able to grasp the segmental phonological information, i.e. the onsets and rhymes, accurately. Further learning trials are needed for them to discriminate and remember the specific tone information. Tonal information that acts as supplementary information would build on the existing segmental information and enrich the phonological representation of each newly learned character. This explains why it is generally observed that dyslexic children require much more effort and training in order to accomplish the full acquisition of new words. We therefore suggest that a less demanding PAL task involving lexical syllables may be used to examine the role of PAL in Chinese word learning in future studies.

\section{CONCLUSION}

To the best of our knowledge, this is the first comprehensive study of the extent and nature of tone difficulty in Chinese dyslexic children. While 
general developmental delay is observed in these children, about one-third to one-half of them also show a deficit in some aspects of tone awareness. Chinese dyslexic children also tend to commit more tonal errors than average readers when they learn new visual-verbal associations, which may in turn lead to problems in reading and learning. Given the integral nature of lexical tones and rhymes in Chinese, a rhymed strategy may facilitate children's learning of tones in new pronunciations. With more than one-third of Chinese dyslexic children having a deficit in tone awareness, tone processing tasks should be considered in diagnostic assessment of Chinese dyslexic children.

\section{REFERENCES}

Bradley, L. \& Bryant, P. (I978). Difficulties in auditory organization as a possible cause of reading backwardness. Nature 271, 746-47.

Chan, C. K. K. \& Siegel, L. S. (200I). Phonological processing in reading Chinese among normally achieving and poor readers. Fournal of Experimental Child Psychology 8o, 23-43.

Chen, X., Anderson, R. C., Li, W.-L., Hao, M.-L., Wu, X.-C. \& Shu, H. (2004). Phonological awareness of bilingual and monolingual Chinese children. Fournal of Educational Psychology 96, I42-5 I.

Chow, B. W.-Y., McBride-Chang, C. \& Burgess, S. (2005). Phonological processing skills and early reading abilities in Hong Kong Chinese kindergartners learning to read English as a second language. Fournal of Educational Psychology 97(I), 81-87.

Cutler, A. \& Chen, H. C. (I997). Lexical tone in Cantonese spoken-word processing. Perception \& Psychophysics 59, I65-79.

Dinneen, F. P. (1967). An introduction to general linguistics. New York: Holt, Rinehart and Winston.

Gottardo, A., Chiappe, P., Yan, B., Siegel, L. \& Gu, Y. (2006). Relationships between first and second language phonological processing skills and reading in Chinese-English speakers living in English-speaking contexts. Educational Psychology 26, 367-93.

He, Y.-Q., Wang, Q.-Y. \& Anderson, R. C. (2005). Chinese children's use of subcharacter information about pronunciation. Fournal of Educational Psychology 97, 572-79.

Ho, C. S.-H. \& Bryant, P. (r 997a). Learning to read Chinese beyond the logographic phase. Reading Research Quarterly 32, 276-89.

Ho, C. S.-H. \& Bryant, P. (I997b). Phonological skills are important in learning to read Chinese. Developmental Psychology 33, 946-5 I.

Ho, C. S.-H., Chan, D., Lee, S.-H., Tsang, S.-M. \& Luan, V. H. (2004). Cognitive profiling and preliminary subtyping in Chinese developmental dyslexia. Cognition 9I, 43-75.

Ho, C. S.-H., Chan, D., Tsang, S.-M. \& Lee, S.-H. (2000). The Hong Kong Test of Specific Learning Difficulties in Reading and Writing (HKT-SpLD). Hong Kong: Hong Kong Specific Learning Difficulties Research Team.

Ho, C. S.-H., Chan, D. W.-O., Tsang, S.-M. \& Lee, S.-H. (2002). The cognitive profile and multiple-deficit hypothesis in Chinese developmental dyslexia. Developmental Psychology 38, 543-53.

Ho, C. S.-H., Chan, D. W., Tsang, S.-M., Lee, S.-H. \& Chung, K. K.-H. (2006). Word learning deficit among Chinese dyslexic children. Fournal of Child Language 33, I45-6I.

Ho, C. S.-H., Law, T. P.-S. \& Ng, P. M. (2000). The phonological deficit hypothesis in Chinese developmental dyslexia. Reading and Writing $\mathbf{1 3}, 57-79$.

Ho, C. S.-H. \& Ma, R. N.-L. (I 999). Training in phonological strategies improves Chinese dyslexic children's character reading skills. Fournal of Research in Reading 22, I 3 I-42.

Hu, C.-F. \& Catts, H. W. (1998). The role of phonological processing in early reading ability: what we can learn from Chinese. Scientific Studies of Reading 2, 55-79. 
Huang, H. S. \& Hanley, J. R. (1994). Phonological awareness and visual skills in learning to read Chinese and English. Cognition 54, 73-98.

Huang, H. S. \& Hanley, J. R. ( I 997). A longitudinal study of phonological awareness, visual skills, and Chinese reading acquisition among first-graders in Taiwan. International Fournal of Behavioral Development 2o, 249-68.

Liberman, I. Y., Mann, V.A., Shankweiler, D. \& Werfelman, M. (I982). Children's memory for recurring linguistic and nonlinguistic material relation to reading ability. Cortex $\mathbf{1 8}, 367-75$.

Luo, Q. \& Weekes, B. S. (2004). Tonal dyslexia in Chinese. Brain and Language 9I, IO2-IO3.

McBride-Chang, C. \& Ho, C. S.-H. (2000). Developmental issues in Chinese children's character acquisition. Fournal of Educational Psychology 92, 50-55.

McDougall, S., Hulme, C., Ellis, A. \& Monk, A. (I994). Learning to read: the role of short-term memory and phonological skills. Fournal of Experimental Child Psychology $\mathbf{5 8}$, I I 2-33.

Messbauer, V. C. S. \& de Jong, P. F. (2003). Word, nonword, and visual paired associate learning in Dutch dyslexic children. Fournal of Experimental Child Psychology 84, 77-96.

Olson, R. K., Rack, J. P. \& Forsberg, H. (I 990). Profiles of abilities in dyslexics and readinglevel-matched controls. Poster presented at the Rodin Remediation Academy meeting at Boulder, Colorado, September I990.

Schirmer, A., Tang, S.-L., Penney, T. B., Gunter, T. C. \& Chen, H.-C. (2005). Brain responses to segmentally and tonally induced semantic violations in Cantonese. Fournal of Cognitive Neuroscience $\mathbf{1 7}, \mathrm{I}-\mathrm{I} 2$.

Siok, W. T. \& Fletcher, P. (200I). The role of phonological awareness and visualorthographic skills in Chinese reading acquisition. Developmental Psychology 37, 886-99.

So, D. \& Siegel, L. S. (r 997). Learning to read Chinese: semantic, syntactic, phonological and working memory skills in normally achieving and poor Chinese readers. Reading and Writing 9, I-2 I.

Swan, D. \& Goswami, U. (I997). Phonological awareness deficits in developmental dyslexia and the phonological representation hypothesis. Fournal of Experimental Child Psychology 66, I 8-4I.

Taft, M. \& Chen, H.-C. (I992). Judging homophony in Chinese: the influence of tones. In H.-C. Chen \& O. J. L. Tzeng (eds), Language processing in Chinese, I $5 \mathrm{I}-72$. Amsterdam: Elsevier.

Tsang, K.-K. \& Hoosain, R. (I979). Segmental phonemes and total phonemes in comprehension of Cantonese. Psychologia 22, 222-24.

Windfuhr, K. L. \& Snowling, M. J. (200I). The relationship between paired associate learning and phonological skills in normally developing readers. Fournal of Experimental Child Psychology 8o, 160-73.

Ye, Y. \& Connine, C. M. (I 999). Processing spoken Chinese: the role of tone information. Language and Cognitive Processes 14, 609-630.

Yue, H. O.-K. (1972). Studies in Yue dialects I: Phonology of Cantonese. Cambridge: Cambridge University Press.

Zhou, Y. K. (1980). Precise guide to pronunciation with Chinese phonological roots. Jilin, China: People's Publishing [in Chinese].

Zhou, X.-L., Qu, Y.-X., Shu, H., Gaskell, G. \& Marslen-Wilson, W. (2004). Constraints of lexical tone on semantic activation in Chinese spoken word recognition. Acta Psychologica Sinica 36, 379-92. 